\title{
Cerebrospinal fluid absorption block at the vertex in chronic hydrocephalus: obstructed arachnoid granulations or elevated venous pressure?
}

\author{
Grant A Bateman ${ }^{1,2^{*}}$ and Sabbir H Siddique ${ }^{1,2}$
}

\begin{abstract}
Background: The lack of absorption of CSF at the vertex in chronic hydrocephalus has been ascribed to an elevation in the arachnoid granulation outflow resistance $\left(R_{\text {out }}\right)$. The CSF infusion studies measuring $R_{\text {out }}$ are dependent on venous sinus pressure but little is known about the changes in pressure which occur throughout life or with the development of hydrocephalus.

Methods: Twenty patients with chronic hydrocephalus underwent MR venography and MR flow quantification techniques. The venous outflow pressure was estimated from the sinus blood flow and the cross-sectional area of the transverse sinuses. Adult controls as well as a normal young cohort were selected to estimate the change in sinus pressure which occurs throughout life and following the development of hydrocephalus. Significance was tested with a Student's t-test.

Results: The size of the transverse sinuses was unchanged from the $1^{\text {st }}$ to the $5^{\text {th }}$ decade of life, indicating a stable outflow resistance. However, the blood flow was reduced by $42 \%$, indicating a likely similar reduction in pressure gradient across the sinuses. The sinuses of hydrocephalus patients were $38 \%$ smaller than matched controls, indicating a 2.5 times increase in resistance. Despite the $24 \%$ reduction in blood flow, a significant increase in sinus pressure is suggested.
\end{abstract}

Conclusions: The size of the venous sinuses normally does not change over the age range investigated but sinus pressure is reduced proportional to an age-related blood flow reduction. Hydrocephalus is associated with much smaller sinuses than normal and an elevation in venous pressure may explain the lack of CSF absorption into the arachnoid granulations in chronic hydrocephalus.

Keywords: Chronic hydrocephalus, Normal pressure hydrocephalus, MR venography, Cerebral blood flow, Sagittal sinus pressure

\section{Background}

It is known that all forms of communicating hydrocephalus are associated with a reduction in CSF flow to the vertex, with the fluid refluxing into the ventricles instead [1]. This phenomenon has been suggested to be evidence for a blockage of CSF flow at the vertex. Davson et al. modelled the CSF absorption over the vertex through the arachnoid granulations and into the venous sinuses. He suggested that the intracranial pressure (ICP) should

\footnotetext{
* Correspondence: grant.bateman@hnehealth.nsw.gov.au

'Department of Medical Imaging, John Hunter Hospital, Locked Bag 1, Newcastle Region Mail Center, Newcastle 2310, Australia

${ }^{2}$ Newcastle University Faculty of Health, Callaghan Campus, Newcastle,
} Australia

be dependent on the CSF formation rate $\left(\mathrm{FR}_{\mathrm{CSF}}\right)$, the resistance to flow through the arachnoid granulations $\left(\mathrm{R}_{\text {out }}\right)$ and the sagittal sinus pressure $\left(\mathrm{P}_{\mathrm{SSS}}\right)$. The equation ICP $=R_{\text {out }} \times \mathrm{FR}_{\mathrm{CSF}}+\mathrm{P}_{\mathrm{SSS}}$ was derived to explain this relationship [2]. Ekstedt studied CSF absorption utilizing a mock CSF infusion method. He found the CSF pressure, CSF outflow resistance, CSF formation rate and sagittal sinus pressure did not vary with age, with the sagittal sinus pressure being $7.5 \mathrm{mmHg}$ on average [3]. He went on to show that the reduction in CSF absorption over the vertex in chronic hydrocephalus was due to a significant increase in the CSF outflow resistance [3]. This has remained the accepted explanation for the apparent 
block to CSF flow at the vertex since. It is assumed that the CSF formation rate and sagittal sinus pressures are constants during the test. Under these constraints, if the CSF formation rate is artificially increased by infusion of mock CSF at known rates, and the resultant ICP is measured, then the slope of the line generated when pressure is plotted against flow rate will be the outflow resistance.

The test is heavily dependent on the sinus pressure remaining constant during the course of the study. For example, in a modeling study using 2-day old rats it was found that the sinus walls were more elastic and deformable than in the adult animals. When an infusion study was performed, the venous pressure rose in the younger rats during the test compared to the adults where it was constant. Ignoring the rise in venous pressure overestimated the resistance to CSF flow across the sinus wall fivefold in the juvenile rats compared to when the venous pressures were taken into account. In adult rats, the infusion study was accurate because the venous pressure was a constant [4]. Similarly, it has recently been shown in patients with pseudotumor cerebri and slit ventricle syndrome that the venous pressure does rise during the infusion study and therefore the CSF outflow resistance is overestimated approximately 5 fold in these disorders as well [5]. Could an overestimation of $R_{\text {out }}$ also occur in chronic hydrocephalus? The venous pressure is not routinely measured in an infusion study and has been rarely measured in normal controls due to the invasive nature of retrograde manometry. Ekstedt's finding that the sinus pressure does not change throughout life is also problematic given that the blood flow through the sagittal sinus varies significantly throughout life. At 10 yrs the average flow is approximately $600 \mathrm{ml} / \mathrm{min}$, at 45 years it is $400 \mathrm{ml} / \mathrm{min}$ and at 80 years about $250 \mathrm{ml} / \mathrm{min} \mathrm{[6].}$ Using Ohm's law, where the pressure is dependent on the flow and outflow resistance, maintaining a constant sinus pressure throughout life would require a significant reduction in the cross-sectional area of the sinuses. Whilst we cannot directly study the sinus pressure in normal aging or during hydrocephalus due to the ethical constraints from the invasive nature of manometry, we can measure the blood flow through the sinuses and their cross-sectional areas using non-invasive MRI techniques. Using Poiseuille's law, sinus pressure can be estimated if the constants in the equation can be calculated. We can calibrate the calculation of sinus pressure and obtain a figure for the constants in Poiseuille's law by utilizing the limited available literature on normal sinus pressure at manometry and use the derived equation to study the changes in sinus pressure across normal aging and secondary to chronic hydrocephalus. Thus, the purpose of this study is to measure the venous sinus outflow blood volume and the sinus cross-sectional area in a cohort of individuals with chronic hydrocephalus and compare the estimated sinus pressures with those of a group of age-matched controls and a group of young healthy individuals.

\section{Methods}

Subjects

Patients referred for investigation of chronic hydrocephalus have been routinely studied with MRI at the John Hunter Hospital, Newcastle Australia, from July 2011 to October 2013. As part of the standard protocol, MRV and MR flow quantification studies have been acquired. Twenty patients were enrolled in the study; there were 7 females and 13 males. The mean age was $45 \pm 10$ years. Patients younger than 30 years were excluded to ensure some chronicity of the disease process and those over 65 years were excluded to reduce the likelihood of comorbidity from dementia or atrophy. Patients with chronic idiopathic communicating hydrocephalus without a currently functioning shunt were selected. Eight patients fulfilled the clinical criteria for probable normal pressure hydrocephalus and had received no prior therapy, six patients had hydrocephalus found incidentally on imaging and could be given the diagnosis of LOVA (late onset ventriculomegaly of adults), four were found to have hydrocephalus following investigation of headaches but without gait disturbance and in two there was hydrocephalus presenting with a failed shunt tube confirmed at nuclear cisternography. The controls were selected from a bank of normal patients and volunteers acquired from previously published material [7-9]. The controls were selected from consecutive patients undergoing MRI examinations for indications unrelated to headaches or CSF flow abnormalities where the MRI examination was seen to be without structural abnormality. The normal young patients averaged $10 \pm 4$ years with 5 males and 5 females. The normal adults were selected to match the hydrocephalus patients with a mean age $44 \pm$ 10 years with 8 females and 12 males. There was no clinical suspicion of raised intracranial pressure or significant history of headache in these individuals. The protocol was approved by the Hospital ethics committee and written informed consent was obtained from each patient.

\section{MR and analysis}

All patients were imaged on a $1.5 \mathrm{~T}$ superconducting magnet (Vario; Seimens, Erlangen Germany). The patients were scanned with standard T1 sagittal, T2 and FLAIR axial images as well as a standard $2 \mathrm{D}$ time of flight MR venogram sequence acquired in a slightly oblique sagittal plane. The MR flow quantification sequence was acquired as a phase contrast study with retrospective cardiac gating. The TR was $26.5 \mathrm{msec}$, TE $6.9 \mathrm{msec}$, flip angle $15^{\circ}$, slice thickness $5 \mathrm{~mm}$, matrix $192 \times 512$, FOV 150 and a single excitation. The velocity 
encoding value was $40 \mathrm{~cm} / \mathrm{sec}$. The plane was selected to pass through the sagittal sinus $2 \mathrm{~cm}$ above the torcular and through the mid part of the straight sinus. The planar imaging, as well as the flow quantification raw data, was archived on a hard drive.

The Evan's index was calculated for the hydrocephalus patients with the cross-sectional width of the ventricles being divided by the width of the anterior cranial fossa from inner table to inner table along a line in the same position as the ventricles. The MRV was reconstructed into $5 \mathrm{~mm}$ sagittal slices, with a slice from the right and left half mid-way from the center line to the inner table of the skull selected. At this site, the mid portion of the transverse sinus is in cross-section and the area of the lumen of each sinus was measured by tracing the outline of the sinus using the proprietary measuring tool. The right and left sinuses were added together to obtain the total outflow area. Using the flow data, regions of interest were placed around the sagittal and straight sinuses in each patient. Care was taken to exclude aliasing by retrospectively manipulating the base lines of each resultant graph. Background subtraction was utilized. The addition of the flow from the two sinuses gave the total outflow blood volume. The mean values and standard deviations were calculated for each measurement. The significance of the findings when hydrocephalus was compared with the normal adults was tested using a Student's t-test with a $p$ value less than 0.05 used to indicate significance. The sagittal sinus pressure was estimated for each patient using a modified Poiseuille equation.

\section{Theory behind sagittal sinus pressure estimation}

The pressure in the sagittal sinus in the supine position is dependent on the jugular bulb pressure and the pressure drop which occurs across the sinuses. The jugular bulb pressure is essentially equal to the central venous pressure due to the capacious nature of the jugular veins. There is no significant change in central pressure throughout life [10]. In children 6-14 years the average central venous pressure is $6 \mathrm{mmHg}$ in the supine position [11]. The mean central venous pressure in adults is $5 \pm$ $0.7 \mathrm{mmHg}$ in the supine position [12]. The pressure drop across a vessel is calculated using Poiseuille's equation:

$$
\Delta \mathrm{P}=8 \mu \mathrm{LQ} / \pi \mathrm{r}^{4}
$$

Where $\Delta \mathrm{P}$ is the pressure drop, $\mu$ is the viscosity, $\mathrm{L}$ is the length of the vessel, $Q$ is the fluid flow rate, $\pi$ is the proportionality constant relating the diameter to the circumference of a circle and $r$ is the radius of the vessel. The cross-sectional area (A) of a vessel is given by the equation:

$$
\mathrm{A}=\pi \mathrm{r}^{2}
$$

By squaring both sides we get:

$$
\mathrm{A}^{2}=\pi^{2} \mathrm{r}^{4}
$$

By taking equation 1 and multiplying both the numerator and denominator by $\pi$ we get:

$$
\Delta \mathrm{P}=8 \mu \pi \mathrm{LQ} / \pi^{2} \mathrm{r}^{4}
$$

By using equation 3 we can substitute $A^{2}$ for the denominator in equation 4 :

$$
\Delta \mathrm{P}=8 \mu \pi \mathrm{LQ} / \mathrm{A}^{2}
$$

As the venous sinuses are lined by dura which is attached to bone the length of these sinuses does not change. Similarly, the viscosity of the blood and $\pi$ are constants so equation 5 can be simplified to:

$$
\Delta \mathrm{P}=\mathrm{kQ} / \mathrm{A}^{2}
$$

We can find the value of $\mathrm{k}$ by using known values from the literature. Grady et al. measured the sagittal sinus pressure at manometry in 15 children ranging in ages from 1-17 yr and found the average pressure to be $10 \mathrm{mmHg}$ in the supine position [13]. Iwabuchi et al. measured the sagittal sinus pressure in 11 children mean age $7 \mathrm{yr}$ and found the pressure to be between 10 and $13 \mathrm{mmHg}$ [14]. Pooling the data gives an average pressure of $10.5 \mathrm{mmHg}$. Subtracting the central venous pressure for children $(6 \mathrm{mmHg})$ this gives a pressure drop of $4.5 \mathrm{mmHg}$ across the sinuses. The data from the current study gives the flow rate through the sinuses to be $810 \mathrm{ml} / \mathrm{min}$ and the area of the sinuses to be $73 \mathrm{~mm}^{2}$ for the children studied. Therefore the constant $\mathrm{k}$ in formula 6 can be calculated to be, $4.5 \times(73)^{2} / 810=29.6$. Thus the sagittal sinus pressure can be estimated to be the pressure drop (i.e. equation 6) plus the central venous pressure:

$$
\mathrm{P}_{\mathrm{SSS}}=29.6 \mathrm{Q} / \mathrm{A}^{2}+\mathrm{CVP}
$$

Equation 7 was utilised to estimate the sinus pressures for each group of patients with the findings presented in Table 1 .

\section{Results}

The transverse sinus area data is summarized in Table 2, with the blood flow and estimated venous pressure data summarized in Table 1 . There was no significant difference between the cross-sectional area of the normal young and normal adult groups. The ventricles of the hydrocephalus patients were enlarged, with an Evan's index of $0.47 \pm 0.07$ and the controls all being less than 0.3 . The cross-sectional area of the transverse sinus in the hydrocephalus patients was a $38 \%$ smaller compared to the normal adults $(p=0.0001)$, with the majority of 
Table 1 Sinus blood flow and estimated sinus pressure in normal young and adult patients and in hydrocephalic patients

\begin{tabular}{|c|c|c|c|c|c|}
\hline Group & $\begin{array}{l}\text { Age } \\
\mathrm{Yr}\end{array}$ & $\begin{array}{l}\text { SSS outflow } \\
\mathrm{ml} / \mathrm{min}\end{array}$ & $\begin{array}{c}\text { ST outflow } \\
\mathrm{ml} / \mathrm{min}\end{array}$ & $\begin{array}{c}\text { Total outflow } \\
\mathrm{ml} / \mathrm{min}\end{array}$ & $\begin{array}{c}\text { Estimated sinus pressure } \\
\mathrm{mmHg}\end{array}$ \\
\hline \multicolumn{6}{|c|}{ Normal young $n=10$} \\
\hline Mean & 10 & 620 & 190 & 810 & 10.5 \\
\hline SD & 4 & 160 & 60 & 220 & 3.6 \\
\hline \multicolumn{6}{|c|}{ Normal adult $n=20$} \\
\hline Mean & 44 & 360 & 110 & 470 & 7.7 \\
\hline SD & 10 & 80 & 40 & 110 & 1.1 \\
\hline \multicolumn{6}{|c|}{ Hydrocephalus $n=20$} \\
\hline Mean & 45 & 280 & 75 & 355 & 10.2 \\
\hline SD & 10 & 60 & 40 & 80 & 5.5 \\
\hline$p$ value & 0.81 & $0.002^{*}$ & $0.01^{*}$ & $0.001^{*}$ & $0.008^{*}$ \\
\hline
\end{tabular}

Mean +/- standard deviation; SSS: superior sagittal sinus, ST: straight sinus, ${ }^{*}$ : t-test $p$ value $<0.05$ normal adults versus hydrocephalic patients.

this reduction occurring on the right side. On average the right transverse sinus represented $59 \% \pm 22 \%$ of the total sinus area in the controls and $55 \% \pm 22 \%$ in the adult hydrocephalus patients (Table 2). As expected, there was a lower sinus blood flow in the normal adults compared to the normal young, and the estimated sinus pressure was reduced proportional to the blood flow. The venous sinus blood flow in the hydrocephalus patients was reduced by $24 \%$ compared with the normal adults $(p=0.001)$. The estimated out flow pressure in the hydrocephalus patients was $32 \%$ larger than the normal adults $(p=0.008$, Table 1$)$.

\section{Illustrative case}

This 32 yr old male had communicating hydrocephalus diagnosed as a child and had required many shunt

Table 2 Cross-sectional area of the transverse sinuses measured by MR imaging in normal young and adult patients and in hydrocephalic patients

\begin{tabular}{lcccc}
\hline Group & $\begin{array}{c}\text { Age } \\
\text { Yr }\end{array}$ & $\begin{array}{c}\text { Right TS } \\
\mathbf{m m}^{\mathbf{2}}\end{array}$ & $\begin{array}{c}\text { Left TS } \\
\mathbf{m m}^{\mathbf{2}}\end{array}$ & $\begin{array}{c}\text { Total area } \\
\mathbf{m m}^{\mathbf{2}}\end{array}$ \\
\hline Normal young $\mathrm{n}=10$ & 10 & 47 & 27 & 73 \\
Mean & 4 & 15 & 19 & 26 \\
SD & & & & \\
Normal adult $\mathrm{n}=20$ & 44 & 43 & 29 & 72 \\
mean & 10 & 19 & 15 & 16 \\
SD & & & & 45 \\
Hydrocephalus $\mathrm{n}=20$ & 45 & 25 & 20 & 15 \\
mean & 10 & 11 & 10 & $0.0001^{*}$ \\
SD & 0.81 & $0.001^{*}$ & $0.04^{*}$ & \\
$p$ value & & & & \\
\hline
\end{tabular}

Values are means +/- standard deviation, TS, transverse sinus; *: t-test $p$ value $<0.05$ normal adults versus hydrocephalus patients. revisions over the years. His most recent revision was in July 2013 where a Medtronic medium pressure valve with an opening pressure of about $7 \mathrm{mmHg}$ was inserted. A baseline MRI study was performed and this confirmed a normal ventricular size (Figure 1A). Three months later following another shunt obstruction, the shunt was removed and a Rickham's reservoir inserted to gauge shunt dependence. A follow-up MRI in October confirmed the ventricular enlargement (Figure 1B). Whilst the shunt was working, the venous sinuses appeared normal (Figure 1C), with the total cross-sectional area of the transverse sinuses being $61 \mathrm{~mm}^{2}$, which was comparable to the controls. The venous outflow volume was $369 \mathrm{ml} / \mathrm{min}$. The estimated pressure in the sagittal sinus was $7.9 \mathrm{mmHg}$ based on the sinus area and the volume of flow. Figure 1D is the appearances of the sinuses after shunt removal and all the sinuses appear slightly smaller. The projection images are misleading as to the degree of this change, however, the total transverse sinus area was much less than previously noted at $35 \mathrm{~mm}^{2}$. The blood flow had also reduced at $245 \mathrm{ml} / \mathrm{min}$. The estimated sagittal sinus pressure was $10.9 \mathrm{mmHg}$. At this point, retrograde manometry was performed to check the venous pressure and exclude a focal stenosis, which could be a target for treatment. The manometry confirmed the pressure at the base of the sagittal sinus to be $11 \mathrm{mmHg}$ compared to atmospheric pressure at the external auditory meatus in the supine position. No focal stenosis was found. At this time, overnight manometry using the reservoir confirmed the CSF pressure to be 13-14 mmHg. Using a modified Masserman technique the drain pressure was lowered to $3 \mathrm{mmHg}$ below the opening pressure and the CSF collected for $24 \mathrm{~h}$. The estimated CSF formation rate was $0.22 \mathrm{ml} / \mathrm{min}$. The $50 \%$ change in cross-sectional area of the sagittal sinus was confirmed on T2 images 


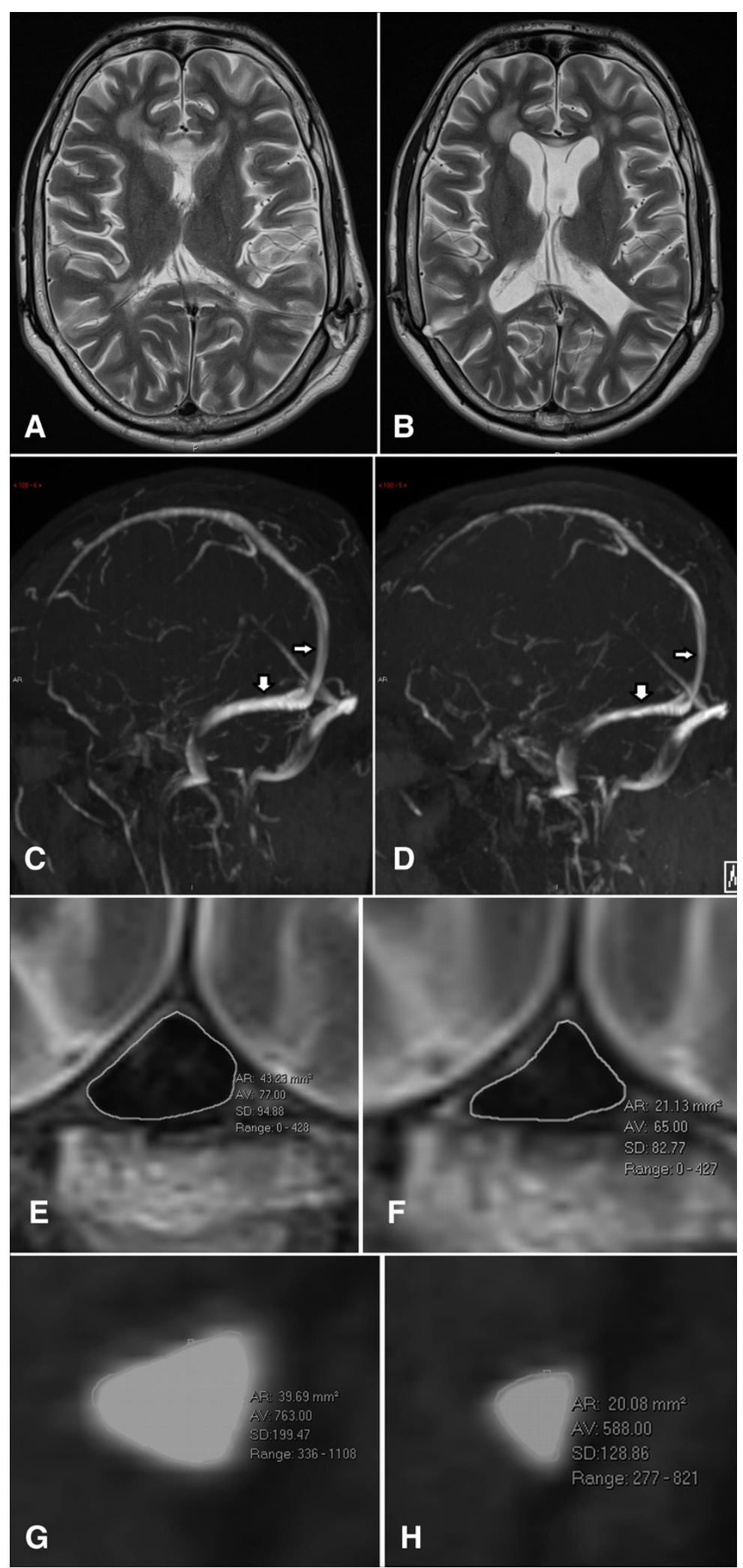

Figure 1 (See legend on next page.) 
(See figure on previous page.)

Figure $1 \mathrm{MRI}$ imaging of a chronic hydrocephalus patient before and after shunt failure. A A T2 axial image of a 32 year-old male with chronic hydrocephalus and a left occipital shunt currently functioning. B A T2 axial image following removal of the shunt showing enlargement of the ventricles. C The MR venogram with functioning shunt appears normal, the thin arrow indicates the sagittal sinus and the thick the dominant transverse sinus. D The MR venogram with the shunt removed shows the sagittal and transverse sinuses to be smaller than previously. This is most easily seen at the level of the arrows. E A T2 axial image of the sagittal sinus $2 \mathrm{~cm}$ above the torcular taken at the level of the thin arrows in $\mathbf{C}$ and $\mathbf{D}$ ) showing the cross-sectional area of the lumen to be $43 \mathrm{~mm}^{2}$. $\mathbf{F}$ The follow-up T2 axial image at the same level as 1e but with shunt removed shows the lumen to be $21 \mathrm{~mm}^{2}$. G A sagittal reconstruction of the mid portion of the right transverse sinus (at approximately the level of the thick arrows above) taken from the MRV raw data shows the sinus to be $40 \mathrm{~mm}^{2}$ in area. $\mathbf{H}$ The same reconstruction as $1 \mathrm{~g}$ following shunt removal shows the sinus area to be $20 \mathrm{~mm}^{2}$.

taken $2 \mathrm{~cm}$ above the Torcular (Figure 1E, F) and the $50 \%$ reduction in right transverse sinus area is shown in Figures $1 \mathrm{~g}$ and $1 \mathrm{~h}$.

\section{Discussion}

The literature surrounding the investigation of chronic hydrocephalus abounds with papers utilising various forms of infusion or bolus injection to discover the out flow resistance or $R_{\text {out }}$. All of these studies are based on Davson's equation, which as previously discussed is in the form:

$$
\mathrm{ICP}=\mathrm{R}_{\text {out }} \times \mathrm{FR}_{\mathrm{CSF}}+\mathrm{P}_{\mathrm{SSS}}
$$

We can see that the sagittal sinus pressure is an important element in the calculation of $R_{\text {out }}$ but the sinus pressure is almost never measured. It is either calculated from Davson's equation itself (circular reasoning) or assumed to be a constant. Calculations of the sagittal sinus pressure by Ekstedt suggested that the sinus pressure does not change throughout life [3] but as already discussed, this would appear to be unlikely. The purpose of the current study was to estimate the sinus pressure using a non-invasive technique based on a modified Poiseuille equation, which is therefore independent of Davson's equation. This will be used to test how well infusion studies perform throughout life and following the development of communicating hydrocephalus.

The current study utilised a modification of Poiseuille's equation using vascular area and blood flow data obtained from the current study. The proportionality constant in the equation was derived from manometry pressure measurements in children obtained from the literature (see methods). The mean sinus pressure for normal children obtained from the literature was $10.5 \mathrm{mmHg}$. The derived equation was then used to predict the sinus pressures in a normal adult cohort independent of the literature. A mean value of $7.7 \mathrm{mmHg}$ was obtained. This compares well to Ekstedt's reference value for the sinus pressure of $7.5 \mathrm{mmHg}$ [3]. Martins et al. measured the sagittal sinus pressure in adults aged 18 to $60 \mathrm{yr}$ and found that in the 9 individuals where the CSF pressure was independent of the ICP, the sinus pressure averaged $8.0 \mathrm{mmHg}$ [15] which again is very similar to the figure predicted by the current study. Iwabuchi et al. found the sinus pressure to be between 4.8 and $9.1 \mathrm{mmHg}$ in adults of mean age 45 years, the range depending on the technique used [14]. Therefore, the current technique appears to correlate well with the available literature for adults indicating an acceptable precision. These findings indicate that the sinus pressure is reduced with age. The cross-sectional area of the sinuses does not appear to change from the first decade to the fifth, indicating the venous outflow resistance is unchanged throughout this period of normal life. The reduction in pressure appears to be directly proportional to the reduction in blood flow.

\section{Davson's equation revisited}

Having established a normal range for sinus pressures, we can test Davson's equation by utilising the most up to date figures available in the literature for the ICP, $R_{\text {out }}$ and $F R_{C S F}$ and calculate the sinus pressure using this technique. In a large study, the average CSF pressure in 10-year old children was found to be $14.6 \mathrm{mmHg}$ [16]. The $R_{\text {out }}$ has been found to depend linearly with age, with the regression line being; $9.88+0.075 \times$ Age in $\mathrm{mmHg} / \mathrm{ml} / \mathrm{min}$ [17]. This gives a $\mathrm{R}_{\text {out }}$ of $10.63 \mathrm{mmHg} /$ $\mathrm{ml} / \mathrm{min}$ at 10 years. The CSF formation rate is highest in children and young adults, being about $0.4 \mathrm{ml} / \mathrm{min}$ and decreases with age to about $50 \%$ of this value at age 70 years [18]. Therefore, Davson's equation predicts an average sinus pressure of $10.3 \mathrm{mmHg}(14.6-10.63 \times 0.4)$ in children with a pressure gradient across the arachnoid granulations of $4.3 \mathrm{mmHg}$ for CSF to flow. This sinus pressure correlates well with the literature $(10.5 \mathrm{mmHg})$. Similarly, in normal middle age, the CSF pressure in a very large study averaged $11.5 \mathrm{mmHg}$ at 45 years [19]. Using the equation as discussed above, the $R_{\text {out }}$ at 45 years would be $13.3 \mathrm{mmHg} / \mathrm{ml} / \mathrm{min}$. The CSF formation rate is reduced by $50 \%$ in old age, and its reduction is said to be linear throughout life [20]. Therefore, we can estimate a $25 \%$ reduction in middle age giving a figure of $0.3 \mathrm{ml} / \mathrm{min}$. Thus, Davson's equation estimates the sinus pressure to be $7.5 \mathrm{mmHg}(11.5-13.3 \times 0.3)$ with a pressure gradient of $4 \mathrm{mmHg}$ across the arachnoid granulations in middle age. This sinus pressure is similar to the published literature, and the findings in the current study $(7.7 \mathrm{mmHg})$, indicating that CSF 
infusion studies are probably quite accurate in normal individuals.

In patients with chronic hydrocephalus of average age 54 years, the average CSF pressure was found to be $1.5 \mathrm{mmHg}$ higher than the control group [20], which would give a CSF pressure of $13 \mathrm{mmHg}$ at 45 years. The average CSF formation rate in the hydrocephalus patients was $0.25 \mathrm{ml} / \mathrm{min}$ [20]. In the Dutch normalpressure hydrocephalus study, a good outcome from treatment of NPH was found to be in individuals with a $\mathrm{R}_{\text {out }}$ greater than $18 \mathrm{mmHg} / \mathrm{ml} / \mathrm{min}$ but averaging approximately $24 \mathrm{mmHg} / \mathrm{ml} / \mathrm{min}$ [21]. Similarly, Czosnyka et al. noted that the upper limit of normal for $\mathrm{R}_{\text {out }}$ is about $12 \mathrm{mmHg} / \mathrm{ml} / \mathrm{min}$, with $\mathrm{NPH}$ patients often being twice this amount [22]. Thus, the $\mathrm{R}_{\text {out }}$ in chronic hydrocephalus is about $24 \mathrm{mmHg} / \mathrm{ml} / \mathrm{min}$. Therefore, Davson's equation estimates the venous pressure to be $7 \mathrm{mmHg}(13-24 \times 0.25)$ in chronic hydrocephalus with a pressure gradient across the arachnoid granulations of $6 \mathrm{mmHg}$. We can see there is a discrepancy between the current study and infusion studies in hydrocephalus. Infusion studies predict a normal sagittal sinus pressure in hydrocephalus $(7 \mathrm{mmHg}$ ) but the estimation of the sinus pressure based on flow and area of the sinuses suggests $10.2 \mathrm{mmHg}$ or $3.2 \mathrm{mmHg}$ higher. Which figure is correct? There is almost no information in the literature regarding sinus pressure in chronic hydrocephalus. Hash et al. noted that an attempt to shunt CSF directly into the sagittal sinus in a patient with NPH failed because the sinus pressure was $1 \mathrm{mmHg}$ higher than the CSF pressure (i.e. elevated) and there was no pressure gradient for CSF absorption [23]. In another study, a prediction of an elevation in sinus pressure of $3-4 \mathrm{mmHg}$ above normal in chronic hydrocephalus was made based on evidence of increased collateral flow bypassing the sinuses [24]. In a kaolin dog model of chronic hydrocephalus, the initial phase was associated with an elevation in CSF and sinus venous pressure, with a normal CSF to sagittal sinus gradient. In the chronic phase, the CSF pressure returned to normal and there was some reduction in sinus pressure but it remained elevated with loss of the pressure gradient across the arachnoid granulations [25]. Similarly, in a rat model of hydrocephalus, there was loss of the pressure gradient between the CSF and sinus during infusion studies with the venous pressure rising linearly with CSF pressure [26]. The illustrative case in the current study appears similar to this literature. Without a shunt, the sinus pressure was $11 \mathrm{mmHg}$ and the CSF pressure $13-14 \mathrm{mmHg}$, giving a gradient across the arachnoid granulations of 2$3 \mathrm{mmHg}$. We know from the predictions of Davson's equation that in normal middle aged subjects, a gradient pressure of about $4 \mathrm{mmHg}$ is required for CSF to flow. Therefore, the lack of absorption at the vertex appears to be due to an unfavourable pressure gradient and not blocked granulations in this case (in the later instance the gradient pressure should have been increased). Similarly, the pooled data suggests a CSF pressure of $13 \mathrm{mmHg}$ in chronic hydrocephalus with a sinus pressure of $10.2 \mathrm{mmHg}$, giving a gradient across the granulations of $2.8 \mathrm{mmHg}$ and therefore no CSF flow.

The current study would tend to suggest that infusion studies underestimate the venous pressure in hydrocephalus. If we corrected Davson's equation for a sinus pressure of $10.2 \mathrm{mmHg}$, then in order for the equation to balance, either the $R_{\text {out }}$ or the CSF formation rate must have been over estimated. The estimate of the CSF formation rate is made by reducing the CSF pressure significantly and measuring the CSF flow required to maintain this pressure. It is said the CSF formation rate is not altered by CSF pressure, so it is unlikely to be overestimated [27]. In the illustrative case the CSF formation rate was $0.22 \mathrm{ml} / \mathrm{min}$ which compares well with the literature [20]. Thus, the $R_{\text {out }}$ is probably at fault. The $R_{\text {out }}$ corrected for a sinus pressure of $10.2 \mathrm{mmHg}$ would average $11.2 \mathrm{mmHg} / \mathrm{min} / \mathrm{min}((13-10.2) / 0.25)$ for the hydrocephalus cohort in order to balance Davson's equation. Thus, if the sinus pressure figure of $10.2 \mathrm{mmHg}$ is correct, then the $R_{\text {out }}$ in chronic hydrocephalus is actually normal. Therefore, it is being overestimated two fold by infusion studies. In the illustrative case, the ICP whilst the ventricular drain was monitored averaged $13.5 \mathrm{mmHg}$, the formation rate was $0.22 \mathrm{ml} / \mathrm{min}$ and the sinus pressure was $11 \mathrm{mmHg}$. Therefore Davson's equation gives the actual $R_{\text {out }}$ to be $(13.5-11) / 0.22=11.4 \mathrm{mmHg} / \mathrm{ml} / \mathrm{min}$ in this case which is normal and similar to the pooled data figure just discussed.

\section{A cause for $\mathbf{R}_{\text {out }}$ overestimation}

In a recent study, $R_{\text {out }}$ was found to be overestimated if the venous pressure increased during the course of the infusion study. The degree of this overestimation was dependent on the proportion of the CSF pressure which was fed back to the sinuses. In pseudotumor cerebri, if $80 \%$ of the increase in CSF pressure occurring during the study was fed back to the sinuses then the $R_{\text {out }}$ was overestimated 5 fold i.e. if the CSF pressure was raised by $10 \mathrm{mmHg}$ during the test and collapse of the sinuses allowed them to increase in pressure by $8 \mathrm{mmHg}$, then the test would overestimate a normal $R_{\text {out }}$ as being elevated five times normal [5]. The two fold overestimation found in the current study could be accounted for by a feedback percentage of $50 \%$. In the illustrative case, whilst the shunt was working the CSF pressure was set by the valve at about $7 \mathrm{mmHg}$ and the estimate of the sinus pressure was $7.9 \mathrm{mmHg}$. When the shunt was removed, the CSF pressure went up to about $13.5 \mathrm{mmHg}$ or an increase of $6.5 \mathrm{mmHg}$. The sinus pressure went up 
to $11 \mathrm{mmHg}$ or an increase in pressure of $3.1 \mathrm{mmHg}$. Therefore, the increase in CSF pressure increased the sinus pressure by passive collapse. The feedback percentage was $50 \%$. Thus, if an infusion study were performed it would overestimate the $R_{\text {out }}$, in this case two fold due to the collapse of the sinuses (i.e. to about $22.8 \mathrm{mmHg} / \mathrm{ml} / \mathrm{min}$ ).

How wide spread is this problem? Obviously if infusion studies are accurate in normal patients, then the sinuses of normal patients do not collapse to any significant degree. In a study where ICP was altered by the addition or removal of CSF, nine of twelve patients showed no change in sinus pressure, despite the CSF pressure being raised by up to $75 \mathrm{mmHg}$. Therefore, there was no venous collapse in these cases and an infusion study would be accurate. In the remaining three patients the sagittal sinus pressure increased by $12 \mathrm{mmHg}$ during a $20 \mathrm{mmHg}$ elevation in CSF pressure (about a $60 \%$ feedback fraction). In one of these patients, a venogram showed a partial collapse of both the sagittal and transverse sinuses during the raised CSF pressure [15] (similar to the illustrative case). If an infusion study were performed on these three individuals it would overestimate $R_{\text {out }}$ by over two fold.

\section{The underlying pathophysiology of chronic hydrocephalus}

If the venous pressures rise by $3 \mathrm{mmHg}$ in chronic hydrocephalus, why do the CSF pressures increase by only $1.5 \mathrm{mmHg}$ [20]? A moderation of the CSF pressure would require a parallel CSF outflow pathway, other than the arachnoid granulations, to reduce the total outflow resistance and make up for the unfavourable gradient pressure across the granulations. We know there is transependymal CSF absorption in hydrocephalus [28] and this may provide a parallel pathway. It has been suggested that capillary absorption is not possible because the CSF pressure would need to be above the capillary pressure and the capillaries would collapse [29]. However, the absorption of water across a capillary bed depends on all the Starling forces not just the hydrostatic pressure. It has been estimated that no net absorption or filtration of water would occur with an average capillary bed pressure of $32 \mathrm{mmHg}$ in the brain [30]. If the capillary bed were reduced from $32 \mathrm{mmHg}$ to anywhere above $13 \mathrm{mmHg}$, then the capillaries would absorb water but maintain their blood flow at a lower level. Below $13 \mathrm{mmHg}$ the capillaries would start to collapse and blood flow would cease. In chronic hydrocephalus the subependymal white matter is ischemic [31, 32]. Therefore, there is a reduction in blood flow at a reduced capillary pressure, bringing about bulk water absorption and moderating the CSF pressure.

If the venous pressure is raised why don't all patients have small ventricles like pseudotumor cerebri? Whether or not the ventricles dilate depends on brain turgor. If the brain is stiff the ventricles will not dilate, if it is more compliant they will. Brain turgor is predominantly affected by the medullary venous pressure [5]. If the sinuses collapse during an elevation in CSF pressure and $80-90 \%$ of the CSF pressure is fed back to the veins, then the medullary veins will be close to CSF pressure and no ventricular dilatation will ensue i.e. pseudotumor cerebri or slit ventricle syndrome [5]. If the feedback fraction is $50 \%$ then the venous pressure will lag behind the CSF pressure. Also, the subependymal white matter is ischemic. Therefore, the medullary pressure is lower, so brain turgor is less in this region, and the ventricles may enlarge [5].

\section{Study limitations}

The present study limits its scope to patients between the ages of 30 and 65 years because of the risk of significant co-morbidity from dementia and atrophy in older patients. Therefore, the applicability to NPH patients in the age group over 65 may be limited until further research is done. The methods utilise MRI, which requires quiet respiration in a supine patient, so it is difficult to draw conclusions as to how the sinuses may react to the upright posture or valsalva manoeuvre. These limitations are common to most hydrocephalus research. The central venous pressures were not measured directly but estimated to be normal, given the patients were not morbidly obese or in right heart failure, this is probably justified.

Poiseuille's equation assumes laminar flow in a uniform cylinder with rigid smooth walls. It is obvious that the sinuses have bends in the sigmoid region, there is some irregularity to the walls and probably wall movement. Thus, the calculations can only be a first approximation to reality. The flow is probably laminar in the sinuses due to the low Reynold's numbers involved. The wall irregularity and bends would be similar between the controls and test patients but the wall pulsation is probably greater in the more compliant sinus walls in the hydrocephalus patients. The flexible walls of the sinus distort in the hydrocephalus patients and the sinuses become more triangular and less cylindrical compared to the controls. As triangular pipes are less efficient, the effect may have been to underestimate the resistance slightly in the hydrocephalus group compared to the controls.

The outflow resistance of both transverse sinuses was added together and both sinuses assumed to act as a single resistor because this considerably simplified the calculations. This would be a reasonable assumption if the ratio of the resistances between the right and left sinuses remained the same in the control and test groups. If there was a significant variation, then depending on the 
magnitude, the pressure would be over or under estimated. The ratio of the average right and left transverse sinus resistances for the adult controls was 2.2:1 and for the hydrocephalus patients 1.56:1. Recalculating the pressure gradient across the sinuses in the hydrocephalus patients taking the parallel resistances into account provided an estimate of $9.95 \mathrm{mmHg}$ compared to the quoted figure of $10.2 \mathrm{mmHg}$ or a $2.5 \%$ error which did not affect the outcome of the study.

\section{Conclusions}

The size of the cerebral venous sinuses normally does not change from the first to the fifth decades of life but there is a reduction in blood flow through the sinuses and sinus pressure is proportional to the age-related blood flow reduction. Chronic hydrocephalus is associated with much smaller sinuses than normal and despite some reduction in blood flow, there is an elevation in venous pressure. This may explain the lack of CSF absorption into the arachnoid granulations because the pressure gradient across the granulations is not favourable in chronic hydrocephalus. An increase in subependymal CSF absorption probably moderates any increase in CSF pressure which would have otherwise occurred.

\section{Abbreviations}

ICP: Intracranial pressure; $F R_{(\mathrm{CSF})}$ : Cerebrospinal fluid formation rate; $P_{\text {sss: }}$ : Pressure in the sagittal sinus; $R_{\text {out }}$ : Cerebrospinal fluid outflow resistance.

\section{Competing interests}

The authors declare we have no conflict of interest concerning the materials or methods used in this study or the findings specified in this paper. There are no competing interests.

\section{Authors' contributions}

GB conceived and designed the study, obtained and processed the data, performed the statistical analysis and wrote the manuscript. SS was involved in patient selection, consent and data acquisition. Both authors have read and approved the final version of the manuscript

\section{Authors' information}

GB is a Neuroradiologist and currently Director or MRI at John Hunter Hospital in Newcastle, Australia. He received a doctorate degree from the University of Sydney for a thesis based on the MRI investigation of CSF disorders. He is a conjoint associate professor at the University of Newcastle in the faculty of health.

SS is a consultant radiologist at John Hunter Hospital and a conjoint lecturer at the University of Newcastle.

\section{Acknowledgements}

The authors would like to acknowledge Dr Ferdinand Miteff who provided the manometry data and Dr John Christie who provided the extra ventricular drainage data in the illustrative case.

Received: 1 April 2014 Accepted: 20 May 2014

Published: 23 May 2014

\section{References}

1. Tator $\mathrm{CH}$, Fleming JFR, Sheppard RD, Turner VM: A radioisotopic test for communicating hydrocephalus. J Neurosurg 1968, 28:327-340.

2. Davson H, Welch K, Segal MB: Physiology and Pathophysiology of the Cerebrospinal Fluid. New York, NY: Churchill Livingstone; 1987:485-521.

3. Ekstedt J: CSF hydrodynamic studies in man. J Neurol Neurosurg Psychiatry 1978, 41:345-353.
4. Jones HC, Gratton JA: The effect of cerebrospinal fluid pressure on dural venous pressure in young rats. J Neurosurg 1989, 71:119-123.

5. Bateman GA: Hypertensive slit ventricle syndrome: pseudotumor cerebri with a malfunctioning shunt? J Neurosurg 2013, 199:1503-1510.

6. Mattle $H$, Edelman RR, Reis MA, Atkinson DJ: Flow quantification in the superior sagittal sinus using magnetic resonance. Neurology 1990, 40:813-815.

7. Bateman GA: Arterial inflow and venous outflow in idiopathic intracranial hypertension associated with venous outflow stenosis. J Clin Neurosci 2008, 15:402-408.

8. Bateman GA: Magnetic resonance imaging quantification of compliance and collateral flow in late onset idiopathic aqueductal stenosis: venous pathophysiology revisited. J Neurosurg 2007, 107:951-958.

9. Bateman GA, Siddique SH: Idiopathic hydrocephalus in children and idiopathic intracranial hypertension in adults: two manifestations of the same pathophysiological process. J Neurosurg (6 Suppl Pediatrics) 2007, 107:439-444.

10. Cléroux J, Giannattasio C, Bolla G, Cuspidi C, Grassi G, Mazzola C, Sampieri L, Seravalle G, Valsecchi M, Mancia G: Decreased cardiopulmonary reflexes with aging in normotensive humans. Am J Physiol 1989, 257:H961-H968.

11. Gazzaniga $A B$, Byrd CL, Stewart DR, O'Connor NE: Evaluation of central venous pressure as a guide to volume replacement in children following cardiopulmonary bypass. Ann Thor Surg 1972, 13:148-154.

12. Norsk P, Foldager N, Bonde-Petersen F, Elmann-Larsen B, Johansen TS: Central venous pressure in humans during short periods of weightlessness. J Appl Physiol 1987, 63:2433-2437.

13. Grady MS, Bedford RF, Park TS: Changes in superior sagittal sinus pressure in children with head elevation, jugular venous compression, and PEEP. J Neurosurg 1986, 65:199-202.

14. Iwabuchi T, Sobata E, Suzuki M, Suzuki S, Yamashita M: Dural sinus pressure as related to neurosurgical positions. Neurosurgery 1983, 12:203-207.

15. Martins AN, Kobrine Al, Larson DF: Pressure in the sagittal sinus during intracranial hypertension in man. J Neurosurg 1974, 40:603-608.

16. Avery RA, Shah SS, Licht DJ, Seiden JA: Reference range for cerebrospinal fluid opening pressure in children. N Eng J Med 2010, 363:891-893.

17. Albeck MJ, Skak C, Nielsen PR, Olsen KS, Borgesen S, Gjerris F: Age dependency of resistance to cerebrospinal fluid outflow. J Neurosurg 1998, 89:275-278.

18. May C, Kaye JA, Atack JR, Shapiro MB, Friedland RP, Rapoport SI: Cerebrospinal fluid production is reduced in healthy aging. Neurology 1990, 40:500-503.

19. Fleischman D, Berdahl JP, Zaydlarova J, Stinnett S, Fautsch MP: Cerebrospinal fluid pressure decreases with older age. PLOS ONE. epub ahead of print December 26, 2012, doi:10.1371/journal.pone.0052664.

20. Silverberg GD, Huhn S, Jaffe RA, Chang SD, Saul T, Heit G, Von Essen A Rubenstein E: Downregulation of cerebrospinal fluid production in patients with chronic hydrocephalus. J Neurosurg 2002, 97:1271-1275.

21. Boon AJ, Tans JTJ, Delwel EJ, Egeler-Peerdeman SM, Hanlo PW, Wurzer HAL, Avezaat CJ, de Jong DA, Gooskens RH, Hermans J: Dutch normal-pressure hydrocephalus study: prediction of outcome after shunting by resistance to outflow of cerebrospinal fluid. J Neurosurg 1997, 87:687-693.

22. Czosnyka M, Czosnyka ZH, Whitfield PC, Donovan T, Pickard J: Age dependence of cerebrospinal pressure-volume compensation in patients with hydrocephalus. J Neurosurg 2001, 94:482-486.

23. Hash CJ, Shenkin HA, Crowder LE: Ventricle to sagittal sinus shunt for hydrocephalus. Neurosurgery 1979, 4:394-400.

24. Bateman GA: The pathophysiology of idiopathic normal pressure hydrocephalus: cerebral ischemia or altered venous hemodynamics? AJNR 2008, 29:198-203.

25. McCormick JM, Yamada K, Rekate HL, Miyake H: Time course of intraventricular pressure change in a canine model of hydrocephalus: its relationship to sagittal sinus elastance. Pediatr Neurosurg 1992, 18:127-133.

26. Jones HC, Gratton JA: The drainage of cerebrospinal fluid in hydrocephalic rats. Z Kinderchir 1989, 44:14-15.

27. Pollay M: Review of spinal fluid physiology: production and absorption in relation to pressure. Clin Neurosurg 1977, 24:254-269.

28. James AE Jr, Strecker EP, Sperber E, Flor WJ, Mertz T, Burns B: An alternative pathway of cerebrospinal fluid absorption in communicating hydrocephalus. Transependymal movement. Radiology 1974, 111:143-146.

29. Mc Comb JG: Recent research into the nature of cerebrospinal fluid formation and absorption. J Neurosurg 1983, 59:369-383. 
30. Bateman GA, Brown KM: The measurement of CSF flow through the aqueduct in normal and hydrocephalic children: from where does it come, to where does it go? Childs Nerv Syst 2012, 28:55-63.

31. Massicotte EM, Buist R, Del Bigio MR: Altered diffusion and perfusion in hydrocephalic rat brain: a magnetic resonance imaging analysis. J Neurosurg 2000, 92:442-447.

32. Momjian S, Owler BK, Czosnyka Z, Czosnyka M, Pena A, Pickard JD: Pattern of white matter regional cerebral blood flow and autoregulation in normal pressure hydrocephalus. Brain 2004, 127:965-972.

doi:10.1186/2045-8118-11-11

Cite this article as: Bateman and Siddique: Cerebrospinal fluid

absorption block at the vertex in chronic hydrocephalus: obstructed

arachnoid granulations or elevated venous pressure? Fluids and Barriers of the CNS 2014 11:11.

\section{Submit your next manuscript to BioMed Central and take full advantage of:}

- Convenient online submission

- Thorough peer review

- No space constraints or color figure charges

- Immediate publication on acceptance

- Inclusion in PubMed, CAS, Scopus and Google Scholar

- Research which is freely available for redistribution 